\title{
Remotely measuring the hydrogen gas by using portable Raman lidar system
}

\author{
In Young $\mathrm{CHOI}^{1}$, Sung Hoon BAIK ${ }^{1 *}$, Young Soo $\mathrm{CHOI}^{2}$ \\ ${ }^{1}$ Division of Quantum Optics, Korea Atomic Energy Research Institute, \\ Deajeon 34507, Korea \\ ${ }^{2}$ Division of Nuclear Robot and Diagnosis, Korea Atomic Energy Research Institute, \\ Deajeon 34057, Korea
}

*Corresponding author: shbaik@kaeri.re.kr

\begin{abstract}
A Raman lidar system is able to detect the range of gas distribution and measure the hydrogen gas concentration remotely. This paper discusses the development of a photon counting Raman lidar system for remotely measuring the hydrogen gas concentration. To verify the developed photon counting Raman lidar system, experiments were carried out in outdoor conditions. As the results indicate, the developed photon counting Raman lidar system is possible to measure 0.66 to $100 \mathrm{vol} \%$ hydrogen gas concentrations at a distance of $30 \mathrm{~m}$. In addition, the measuring average error measured $0.54 \%$ and the standard deviation is $2.42 \%$ at a distance of $30 \mathrm{~m}$.
\end{abstract}

Keywords: Raman lidar, photon counter, hydrogen gas, remote gas detection.

\section{Introduction}

Hydrogen gas is a very important energy resource and it will be used daily in the near future. However, hydrogen gas is very dangerous because it is flammable and explosive at a very low concentration ratio. Therefore, the hydrogen gas leakage detection technique is essentially needed for safety [1].

Various hydrogen gas detection techniques are used such as catalytic combustion sensors, semiconducting oxide sensors, thermal conductivity sensors, and electrochemical sensor owing to their significant advantages such as low cost, high reproducibility, and simple execution [2]. However, these local type sensors affect the airflow direction and difference in hydrogen gas densities from the measurement locations. In addition, these sensors need a large number of sensors to cover a wide area and be attached in the form of a phased array for measuring the hydrogen gas distribution [ $\underline{3}-\underline{7}]$.

A Raman lidar system is one of the remote hydrogen gas detection techniques. It is able to measure the range of the hydrogen gas distribution and hydrogen gas concentration densities remotely $[\underline{1}, \underline{2}, \underline{8}-\underline{13}]$. PRIVALOV suggested the method of the hydrogen 
gas molecules detection by using the Raman lidar system with a $532 \mathrm{~nm}$ wavelength laser [8]; $100 \mathrm{~mJ}$ and $400 \mathrm{~mm}$ diameter telescope was used in 2004 [6]. Laboratory Raman scattering hydrogen gas detection systems have been described by BALL [9] and by NinOMIYA et al. $[\underline{10}, \underline{11}]$. Both systems used Nd:YAG lasers as a light source in the light transmitter devices. NINOMIYA et al. operated a pulsed Nd:YAG laser at the third harmonic of $355 \mathrm{~nm}$ wavelength, $6 \mathrm{~mJ}$ and $170 \mathrm{~mm}$ diameter telescope was used. BALL et al. [9] operated a pulsed Nd:YAG laser at a $355 \mathrm{~nm}$ wavelength, 125 and $250 \mathrm{~mJ}, 100 \mathrm{~mm}$ diameter telescope was used. LiMÉRY et al. [1] $]$ operated a pulsed Nd:YAG laser at the third harmonic of $355 \mathrm{~nm}$ wavelength, $30 \mathrm{~mJ}$ and $152 \mathrm{~mm}$ diameter telescope are used. BAIK et al. [12] developed the Raman lidar system to measuring the hydrogen gas remotely. BAIK et al. used a pulsed Nd:YAG laser at a $355 \mathrm{~nm}$ wavelength, $30 \mathrm{~mJ}$ and suggested the method of the reduce of the background noise signal of the Raman signal to improve the signal-to-noise ratio of the Raman lidar system. Table 1 shows a summary of previous invented Raman lidar system. In general, a Raman lidar system uses a high power pulse laser and large size diameter telescope to measure the Raman signal of the hydrogen gas because a Raman signal is very weak.

This paper discusses the development of the miniaturized photon counting (PC) Raman lidar system. A small size diode pumped pulse laser was used for a laser source with a high repetition rate and small energy pulse. The signal-to-noise ratio of the Raman scattering signal is significantly lower than that of high energy pulse laser and large optical receivers because individual pulse energy is very low. The photon counter system is able to eliminate the background noise signals using a discriminator. To verify

T a b l e 1. Specifications of previously invented Raman lidar system.

\begin{tabular}{|c|c|c|c|c|c|}
\hline & PRIVALOV [ $[\underline{8}]$ & BALL [9] & NiNOMIYA $[\underline{10}, \underline{11}]$ & BAIK [12] & LIMÉRY [13] \\
\hline $\begin{array}{l}\text { Low hydrogen } \\
\text { gas measuring } \\
\text { limit }[\mathrm{vol} \%]\end{array}$ & 0.6 & 0.76 & 0.6 & 0.67 & 2 \\
\hline $\begin{array}{l}\text { Laser max energy } \\
\text { output }[\mathrm{mJ}]\end{array}$ & 100 & 250 & 6 & 30 & 30 \\
\hline Wavelength [nm] & 532 & 355 & 355 & 355 & 355 \\
\hline $\begin{array}{l}\text { Repetition } \\
\text { rate }[\mathrm{Hz}]\end{array}$ & 50 & 10 & 100 & 20 & 20 \\
\hline $\begin{array}{l}\text { Telescope } \\
\text { diameter }[\mathrm{mm}]\end{array}$ & 400 & 100 & 170 & 75 & 152 \\
\hline $\begin{array}{l}\text { Detection } \\
\text { distance }[\mathrm{m}]\end{array}$ & 2 & 50 & 13 & 30 & 85 \\
\hline $\begin{array}{l}\text { Band-pass } \\
\text { filter centre }[\mathrm{nm}]\end{array}$ & 648 & $375,385,395$ & 416.3 & 416 & 416 \\
\hline $\begin{array}{l}\text { Band-pass filter } \\
\text { FWHM [nm] }\end{array}$ & 5 & - & 1.8 & 0.3 & 15 \\
\hline Number of average & 15 & 50 & 64 & 100 & 1200 \\
\hline
\end{tabular}


the developed miniaturized PC Raman lidar system, experiments remotely measuring the hydrogen gas concentration are carried out at a 10,20,30 m distance in outdoor conditions. As the experiment results show, the linearity of the hydrogen gas concentration is very high, the mean measuring error is $0.54 \%$, and the standard deviation is $2.42 \%$ at $30 \mathrm{~m}$.

\section{PC Raman lidar instrumentation}

\subsection{Raman lidar system}

Figure 1 shows a schematic diagram of the on-axis Raman lidar system. The Raman lidar system consists of three major parts. First, a transmitter part is the pulse laser illuminating the laser beam to the target gases. It consists of a pulse laser and beam expander. Second, an optical receiver part measures the Raman signal from the target gases. It consists of optical lenses, a beam splitter, a band-pass filter, and photomultiplier tube (PMTs). Third, electronics parts convert the analogue to digital signal. In general, a high-speed digitizer was used in the Raman lidar system for converting the analogue to digital signal. However, the developed PC Raman lidar system used a photon counter instead of a high-speed digitizer because it eliminated the noise such as

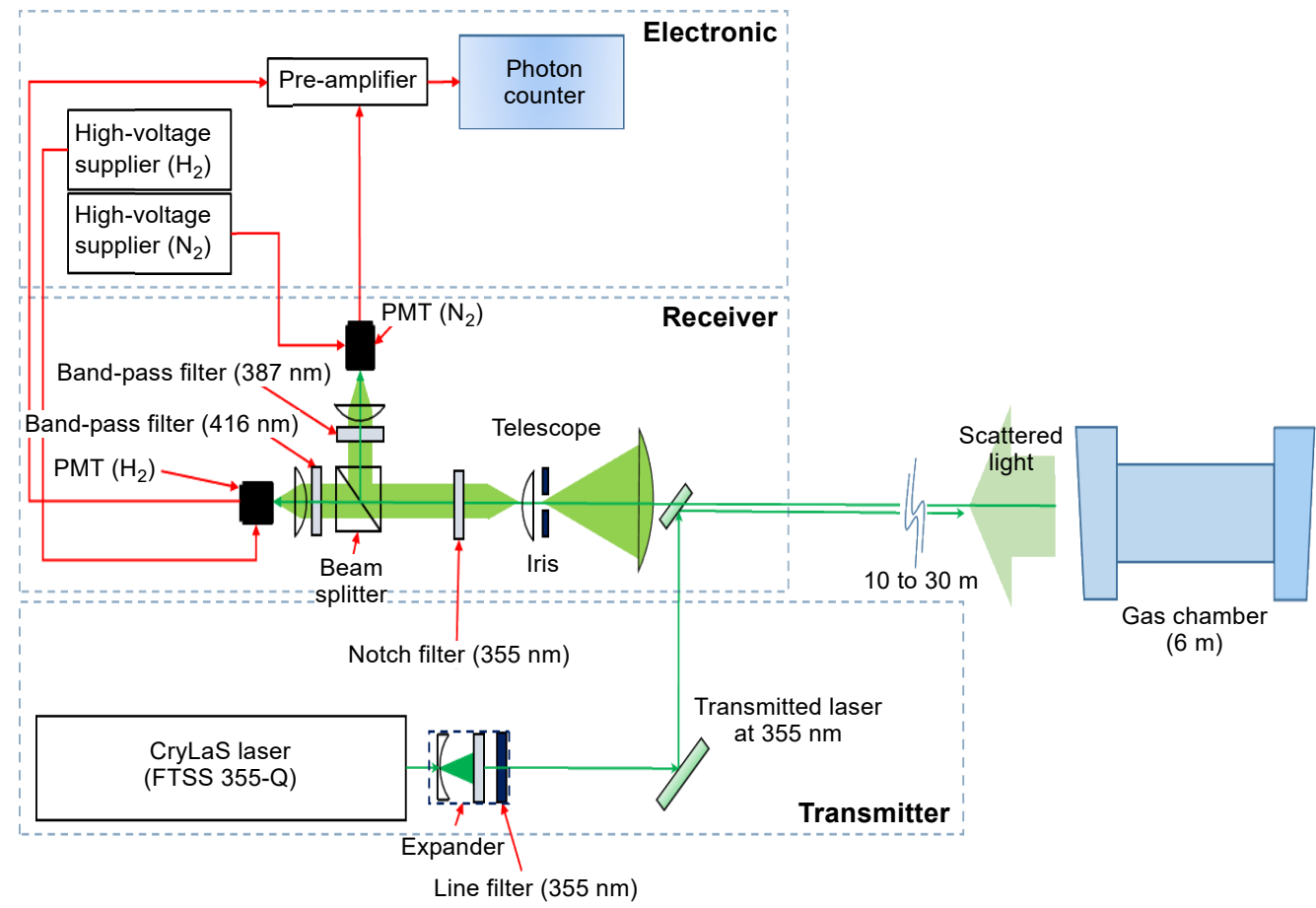

Fig. 1. Schematic diagram of the on-axis PC Raman lidar system. 
T a b l e 2. Specifications of the PC Raman lidar system.

\begin{tabular}{|c|c|}
\hline \multicolumn{2}{|r|}{ Transmitter } \\
\hline Type & Diode pumped laser (CryLaS FTSS 355-Q2) \\
\hline Repetition rate & $10 \mathrm{kHz}$ \\
\hline Pulse width & $1 \mathrm{~ns}$, jitter $\pm 2 \mathrm{~ns}$ \\
\hline Energy & $3 \mu \mathrm{J}$ at $355 \mathrm{~nm}$ (third harmonics) \\
\hline \multicolumn{2}{|r|}{ Optical receiver } \\
\hline Telescope diameter & $75 \mathrm{~mm}$ \\
\hline Band-pass filter $(416 \mathrm{~nm})$ & $416 \mathrm{~nm} \pm 0.15 \mathrm{~nm}$ (for hydrogen Raman signal), $\mathrm{OD}=6$, Alluxa \\
\hline Band-pass filter $(387 \mathrm{~nm})$ & $387 \mathrm{~nm} \pm 0.15 \mathrm{~nm}$ (for nitrogen Raman signal), $\mathrm{OD}=8$, Alluxa \\
\hline Dichroic beam splitter & $\begin{array}{l}\text { Cut-on wavelength } 409 \mathrm{~nm} \pm 3.0 \mathrm{~nm} \text {, Alluxa } \\
\text { - Transmission band ( } 415 \text { to } 850 \mathrm{~nm}>95 \%, T \text { average) } \\
\text { - Reflection band ( } 325 \text { to } 403 \mathrm{~nm}>98 \%, R \text { average) } \\
\text { - Transmitted wavefront error }<0.25 \text { wave RMS at } 632.8 \mathrm{~nm} \\
\text { - Size } 35.6 \times 25.2 \times 1.05 \mathrm{~mm}(\mathrm{H} \times \mathrm{V} \times \mathrm{T})\end{array}$ \\
\hline Notch filter $(355 \mathrm{~nm})$ & $355 \mathrm{~nm} \pm 10 \mathrm{~nm}, \mathrm{OD}=6$ \\
\hline \multicolumn{2}{|r|}{ Electronic } \\
\hline Photon counter & FastComtec, MCS6A, Multiscaler, 400 ps \\
\hline DAQ (data acquisition) & National instrument, NI - USB 6211 (PMT amplifier value control) \\
\hline PMT & $\begin{array}{l}\text { Hamamatsu R9880-U210 }\left(\mathrm{PMT} \mathrm{H}_{2} \text { and PMT N}\right. \\
\text { Photocathode area }=8 \mathrm{~mm} \\
\text { Peak wavelength }=400 \mathrm{~nm} \\
\text { Rise time typical }=0.57 \mathrm{~ns} \\
\text { Transit time typical }=2.7 \mathrm{~ns} \\
\text { Dark current max value (after } 30 \text { min at } 1000 \mathrm{~V} \text { supplied to anode) }=10 \mathrm{nA} \\
\text { Luminous min and max value (anode) }=100 \text { to } 270 \mathrm{~A} / \mathrm{lm} \\
\text { Luminous min and max value (cathode) }=100 \text { to } 270 \mu \mathrm{A} / \mathrm{lm}\end{array}$ \\
\hline Pre-amplifier & Hamamatsu C6438-02 \\
\hline
\end{tabular}

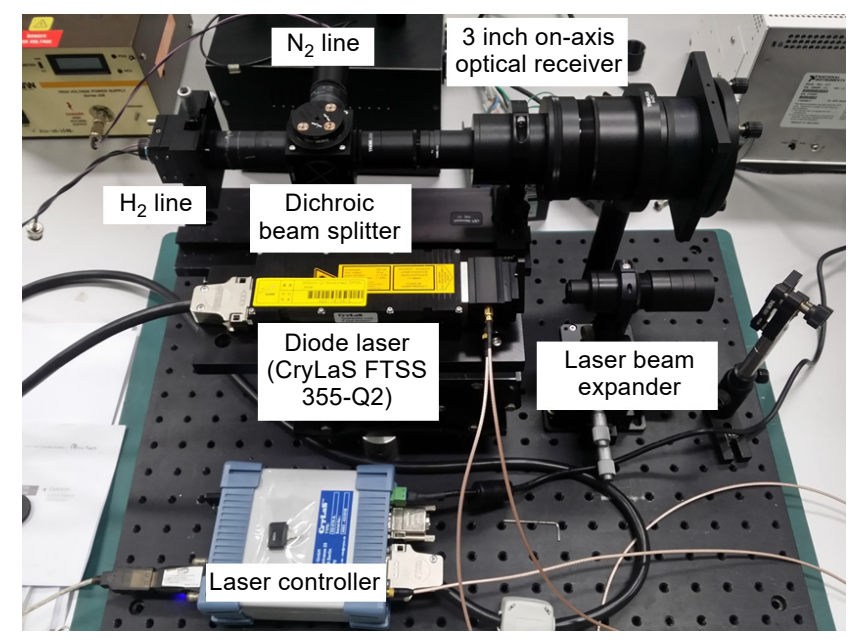

Fig. 2. Photograph of on-axis PC Raman lidar system. 
a laser induced light, ambient light, and fluorescence using the photon counters. Table 2 shows the specifications of the developed PC Raman system. Figure 2 shows a photograph of the PC Raman lidar system.

\subsection{Photon counter}

Figure 3 shows the roles of the discriminator in the photon counter system and Fig. 4 shows the principle of measuring the Raman signal using the photon counter. The amplitude of the Raman photon pulse was affected by pulse laser energy. When using a low pulse energy laser, the amplitude of the Raman photon pulse is weak and distinguished from noise signals. However, a photon counter system has discriminators. A photon counter system counts the Raman photon pulses over the discriminator threshold values. Therefore, noise signals such as a laser induced light, ambient light, and fluorescence are eliminated from the Raman photon pulse counting data. The photon counter measurement data indicate the accumulation of the number of photon pulses in excess

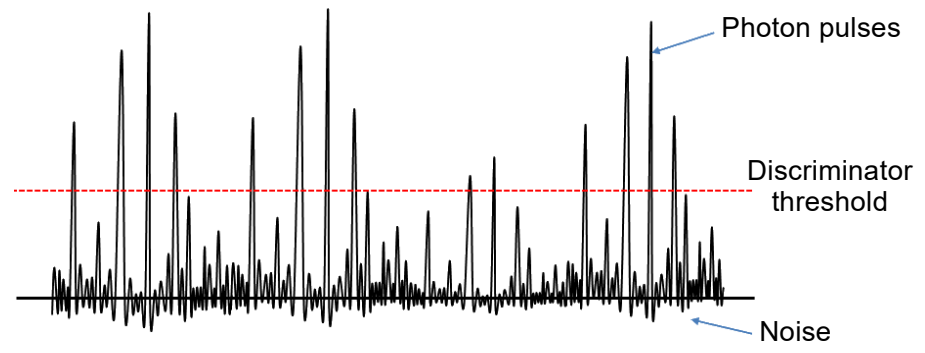

Fig. 3. Role of the discriminator in the photon counter.

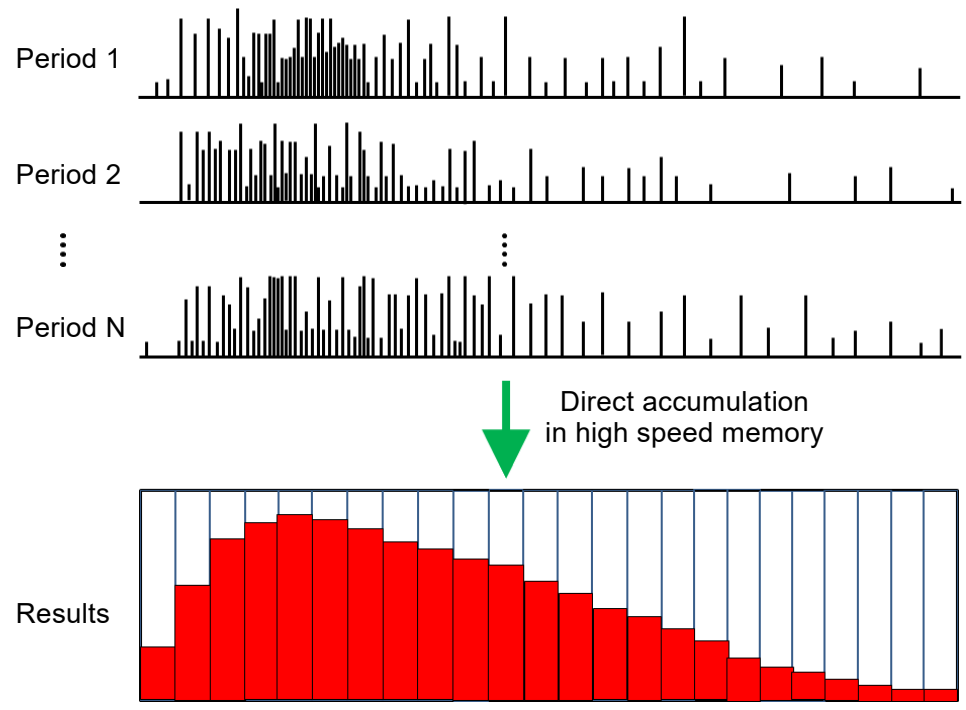

Fig. 4. Principle of measuring the Raman signal using the photon counter. 
$\mathrm{T} \mathrm{a} \mathrm{b} \mathrm{l} \mathrm{e} \mathrm{3.} \mathrm{Specifications} \mathrm{of} \mathrm{the} \mathrm{photon} \mathrm{counter} \mathrm{used} \mathrm{in} \mathrm{the} \mathrm{PC} \mathrm{Raman} \mathrm{lidar} \mathrm{system.}$

\begin{tabular}{ll}
\hline Remark & Specification \\
\hline Trigger channels & 1 start channel (positive and negative selection) \\
Measuring channels & 3 stop channels (each a channel has individual discriminators) \\
Start and stop input threshold & $\pm 1.5 \mathrm{~V}$ (adjustable in steps of $183 \mu \mathrm{V}$ ) \\
Dead time & No dead time between time bins \\
Bin time & $1,2,4,8,16,32$ \\
& (available time resolutions: $400,800,1600,3200,6400,12800 \mathrm{ps)}$ \\
Band width & $10 \mathrm{GHz}, 64$ bit counting results
\end{tabular}

of the discriminator's threshold values, by a large number of individual laser pulses. Table 3 shows the specifications of the photon counter used in the PC Raman lidar system. It detects the time of the incidence of the stop signals (rising, falling or both edges) relative to the start signal with a $400 \mathrm{ps}$ time resolution. In addition, three built-in discriminators can be individually adjusted, and FIFO (first in, first out) memory buffers are enabled.

\subsection{Measuring algorithm of the PC Raman lidar system}

Figure 5 shows the measurement algorithm of the developed PC Raman lidar system. To quantitatively measure the hydrogen gas concentration using the PC Raman liar sys-

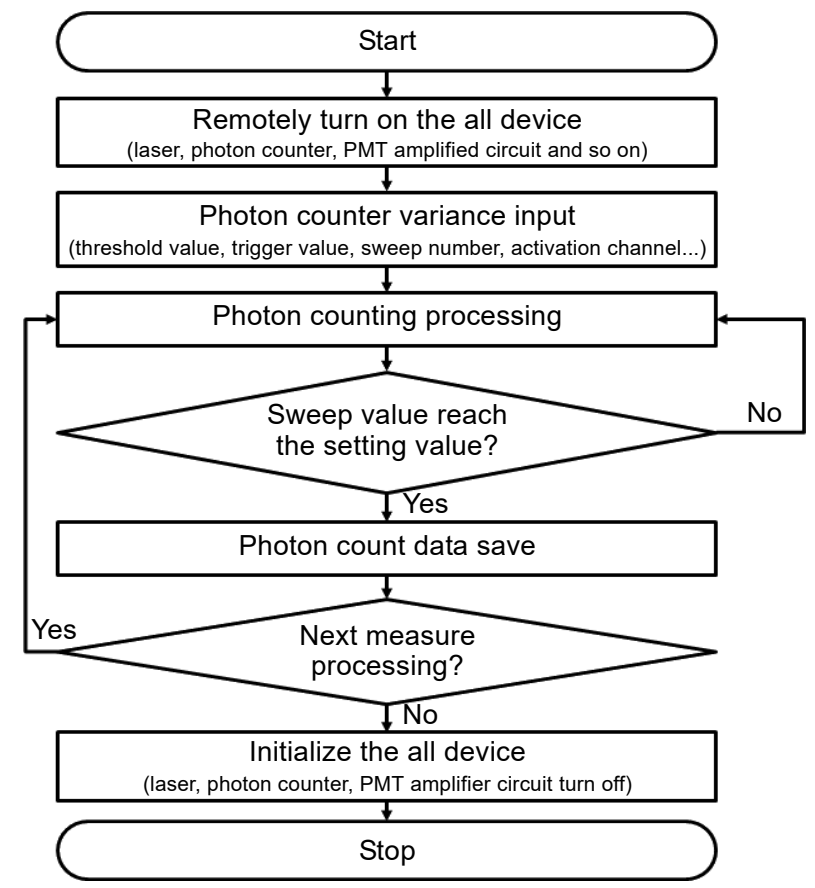

Fig. 5. A measuring algorithm of the PC Raman lidar system. 


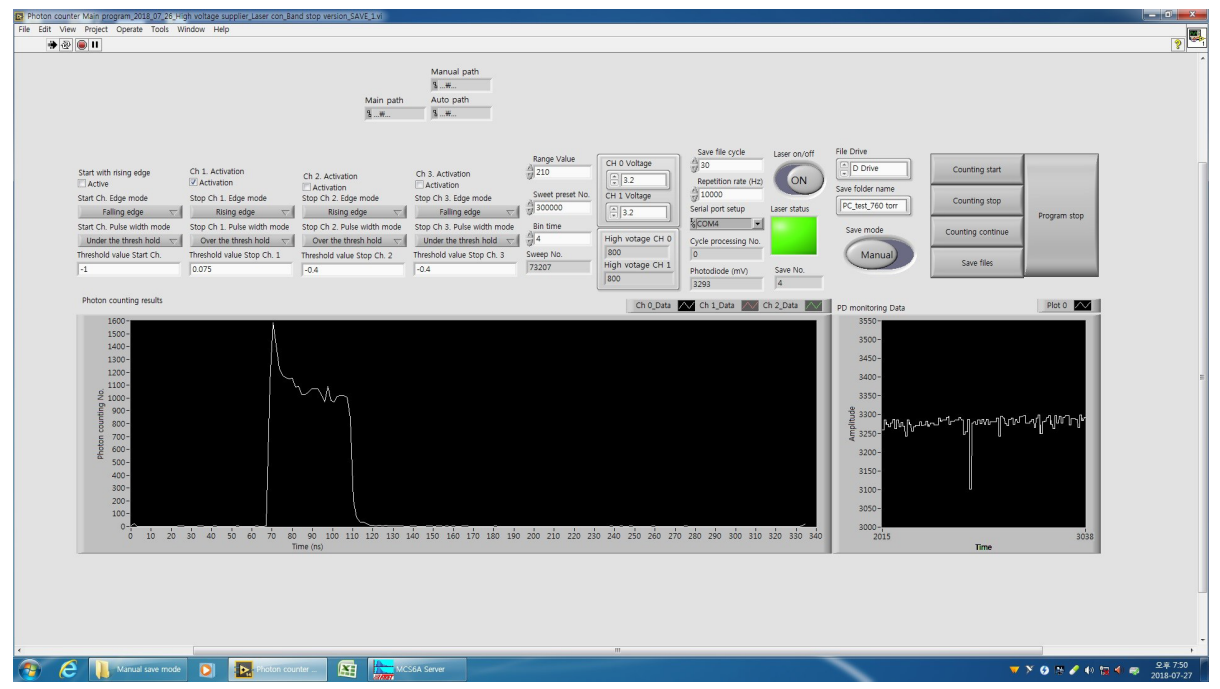

Fig. 6. Interface of the PC Raman lidar system-operating program.

tem, a photon counting process was controlled according to the number of laser pulses because of the accumulation of a number of photon pulses in excess of the discriminator's threshold values by a large number of individual laser pulses. The sweep mode stops the photon counting process when the counts of the laser pulse reach the set-up values. A PC Raman liar system algorithm was implemented using the LabVIEW program platforms. Figure 6 shows the interface of the PC Raman lidar system-operating program. A PC Raman lidar system is able to control the photon counter, pulse laser, and amplifying value of the PMT. It is able to monitor the laser power output and photon counting number.

\section{Experiment}

\subsection{Experimental set-up}

To verify the performance of the PC Raman lidar system, hydrogen gas concentration measuring experiments are carried out. To keep the hydrogen gas concentration and prevent an explosion of hydrogen gas, experiments were carried out using a gas chamber. A gas chamber was located from the distance 10, 20, and $30 \mathrm{~m}$ from the PC Raman lidar system to verify the possible range of the remotely measuring the hydrogen gas distribution by the PC Raman lidar system. Also, Raman signals were measured at the hydrogen gas concentration of $0.66,1.30,3.25,6.36,12.99,19.48,38.96,58.44,77.92$, and $100 \mathrm{vol} \%$ each 10,20 , and $30 \mathrm{~m}$ distance. In addition, the measured minimum time resolution set up is $1.6 \mathrm{~ns}$ in the photon counter (bin time 4 selected) and the threshold value of the discriminator set up is $0.075 \mathrm{~V}$. To compare the quantitative measurement of the hydrogen gas concentrations, Raman signals of the hydrogen gas were measured 
by the PC Raman lidar system during the 300000 laser pulses. To analyze the measurement precision and repeatability of the PC Raman lidar system, 20 replicated experiments on measuring the Raman signal of the hydrogen gas under the same hydrogen gas concentration conditions were conducted. A hydrogen gas is very flammable and explosive. In addition, hydrogen gas has a faster diffusion speeds in the air because it is lighter than the air. The $6 \mathrm{~m}$ gas chamber that had two viewports to transmit the laser pulse was used to keep the hydrogen gas concentration and prevent the explosions. Figure 7 shows a photograph of the $6 \mathrm{~m}$ gas chamber. Table 4 indicates the specification of the hydrogen gas analyzer in the gas chamber.

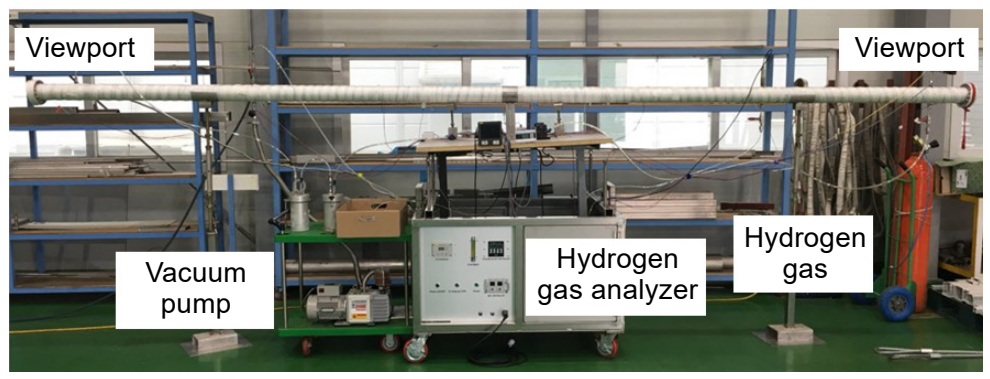

Fig. 7. Photograph of the gas chamber for keeping the hydrogen gas and preventing the explosion.

$\mathrm{T}$ a b l e 4. Specifications of hydrogen gas analyzer

\begin{tabular}{ll}
\hline Remark & Specification \\
\hline Manufacturer & Masskonzept \\
Model & FTC-200 \\
Hydrogen gas measuring range & To 100 vol\% \\
Measuring method & Thermal conductivity \\
\hline
\end{tabular}

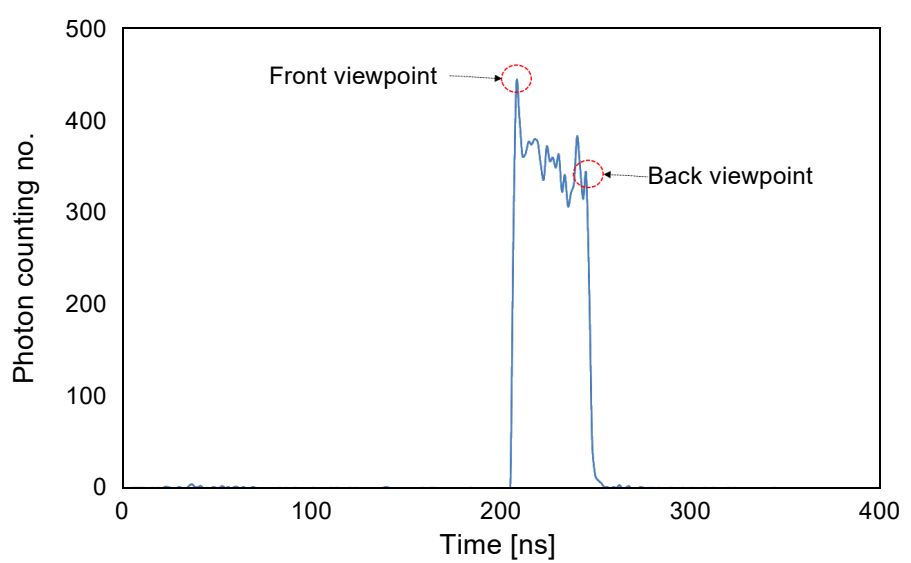

Fig. 8. Hydrogen gas (6.36 vol\%) concentration measuring result at $10 \mathrm{~m}$ distance. 


\subsection{Experimental results}

To measure the Raman signal according to the hydrogen gas concentration, the minimum time resolution of the photon counter was set at $1.6 \mathrm{~ns}$. Therefore, the number of 25 data could be measured from the $6 \mathrm{~m}$ gas chamber using the photon counter. Figure 8 shows the results of the Raman signal of the hydrogen gas in the $6 \mathrm{~m}$ gas chamber by using the PC Raman lidar. The viewport of the $6 \mathrm{~m}$ gas chamber does not perfectly transmit the laser beam. A laser beam was reflected from the viewport and it was combined with the Raman signal of the hydrogen gas. If a Raman signal measured near the viewport of the gas chamber was used for measuring the hydrogen gas concentration, it would involve an error caused by a laser beam. To get rid of the error introduced

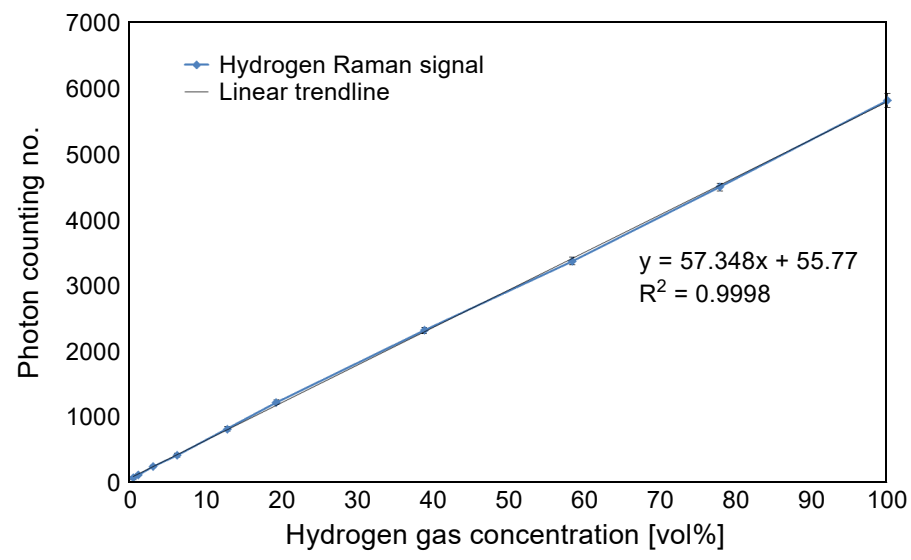

Fig. 9. Hydrogen gas concentration measuring results at $10 \mathrm{~m}$ distance.

$\mathrm{T}$ a b $1 \mathrm{e}$ 5. Hydrogen gas concentration analysis results at $10 \mathrm{~m}$ distance.

\begin{tabular}{lcccl}
\hline $\begin{array}{l}\text { Hydrogen gas } \\
\text { concentration [vol\%] }\end{array}$ & $\begin{array}{l}\text { Photon counting } \\
\text { number }\end{array}$ & $\begin{array}{l}\text { Measuring hydrogen gas } \\
\text { concentration [vol\%] }\end{array}$ & $\begin{array}{l}\text { Measuring } \\
\text { error }\end{array}$ & $\begin{array}{l}\text { Standard } \\
\text { deviation [\%] }\end{array}$ \\
\hline 0.65 & 67.50 & 0.20 & -0.44 & 0.34 \\
1.30 & 112.25 & 0.98 & -0.31 & 0.41 \\
3.25 & 245.50 & 3.31 & 0.06 & 0.53 \\
6.36 & 415.40 & 6.27 & -0.09 & 0.61 \\
12.99 & 815.20 & 13.24 & 0.26 & 0.57 \\
19.48 & 1221.10 & 20.32 & 0.84 & 0.88 \\
38.96 & 2315.25 & 39.40 & 0.44 & 1.05 \\
58.44 & 3368.40 & 57.76 & -0.68 & 1.02 \\
77.92 & 4497.05 & 77.44 & -0.48 & 1.81 \\
100.00 & 5814.20 & 100.41 & 0.41 & 2.17 \\
\hline Average & - & - & 0.40 & 0.94 \\
\hline
\end{tabular}

Remark: All results were measured by the same laser pulse (300000 shot) regardless of the hydrogen gas concentration. 
by a laser beam from the Raman signal, the Raman signal data of the hydrogen gas which measured the mid-point of the gas chamber was used for analyzing quantitatively the hydrogen gas concentration by using the PC Raman lidar system.

Figures 9-11 show the results of the hydrogen gas concentration results according to the measuring distance. Tables 5-7 show the analysis results of the hydrogen gas concentration according to the measuring distance. To analyze the measuring error and standard deviation, the measured hydrogen gas concentration values were calculated based on the linear fitting line of the measured hydrogen Raman signal value.

Table 8 shows the values of the coefficient of the determination, the average value of the measuring errors and the average value of the standard deviation according to the distance. Comparing the $10 \mathrm{~m}$ results with the $30 \mathrm{~m}$ results, average measuring er-

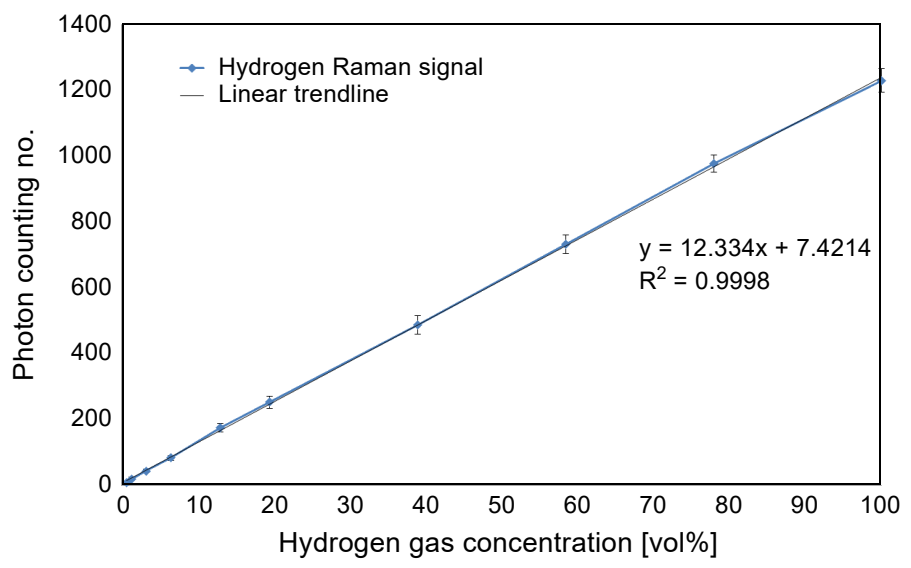

Fig. 10. Hydrogen gas concentration measuring results at $20 \mathrm{~m}$ distance.

$\mathrm{T}$ a b 1 e 6 . Hydrogen gas concentration analysis results at $20 \mathrm{~m}$ distance.

\begin{tabular}{lccll}
\hline $\begin{array}{l}\text { Hydrogen gas } \\
\text { concentration [vol\%] }\end{array}$ & $\begin{array}{l}\text { Photon counting } \\
\text { number }\end{array}$ & $\begin{array}{l}\text { Measuring hydrogen gas } \\
\text { concentration [vol\%] }\end{array}$ & $\begin{array}{l}\text { Measuring } \\
\text { error }\end{array}$ & $\begin{array}{l}\text { Standard } \\
\text { deviation [\%] }\end{array}$ \\
\hline 0.65 & 9.30 & 0.15 & -0.50 & 0.28 \\
1.30 & 20.40 & 1.05 & -0.25 & 0.41 \\
3.25 & 44.6 & 3.01 & -0.23 & 0.41 \\
6.36 & 84.20 & 6.22 & -0.27 & 0.60 \\
12.99 & 175.50 & 13.63 & 0.64 & 1.07 \\
19.48 & 252.90 & 19.90 & 0.42 & 1.47 \\
38.96 & 488.40 & 39.00 & 0.04 & 2.25 \\
58.44 & 732.10 & 58.75 & 0.31 & 2.27 \\
77.92 & 977.80 & 78.68 & 0.75 & 2.19 \\
100.00 & 1229.55 & 99.09 & -0.91 & 2.88 \\
\hline Average & - & - & 0.43 & 1.38 \\
\hline
\end{tabular}

Remark: All results were measured by the same laser pulse (300000 shot) regardless of the hydrogen gas concentration. 


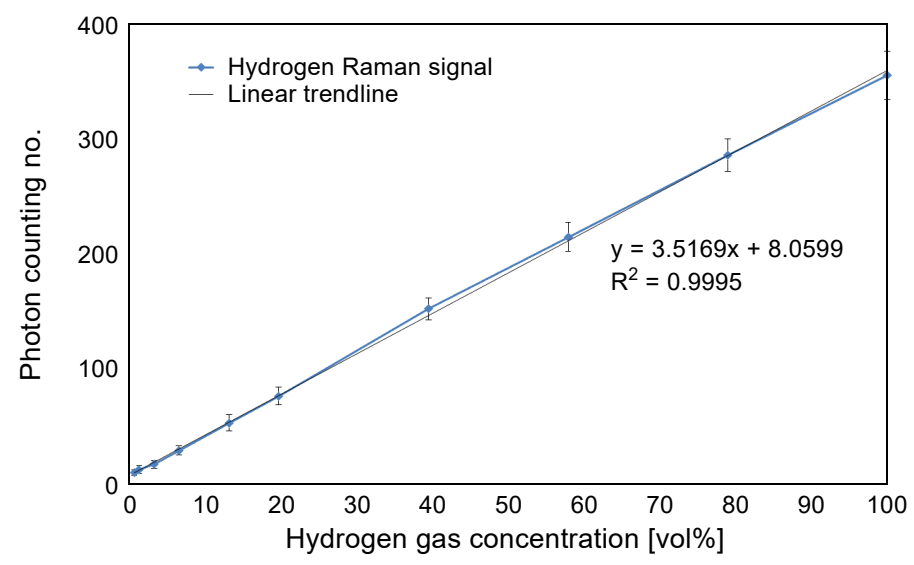

Fig. 11. Hydrogen gas concentration measuring results at $30 \mathrm{~m}$ distance.

T a b 1 e 7 . Hydrogen gas concentration analysis results at $30 \mathrm{~m}$ distance.

\begin{tabular}{lllll}
\hline $\begin{array}{l}\text { Hydrogen gas } \\
\text { concentration [vol\%] }\end{array}$ & $\begin{array}{l}\text { Photon counting } \\
\text { number }\end{array}$ & $\begin{array}{l}\text { Measuring hydrogen gas } \\
\text { concentration [vol\%] }\end{array}$ & $\begin{array}{l}\text { Measuring } \\
\text { error }\end{array}$ & $\begin{array}{l}\text { Standard } \\
\text { deviation [\%] }\end{array}$ \\
\hline 0.66 & 10.25 & 0.62 & -0.04 & 0.63 \\
1.32 & 12.80 & 1.35 & 0.03 & 0.98 \\
3.29 & 17.50 & 2.68 & -0.61 & 0.99 \\
6.58 & 29.55 & 6.11 & -0.47 & 1.14 \\
13.16 & 53.50 & 12.92 & -0.24 & 2.07 \\
19.74 & 76.70 & 19.52 & -0.22 & 2.18 \\
39.47 & 152.70 & 41.13 & 1.65 & 2.27 \\
57.89 & 214.90 & 58.11 & 0.92 & 3.57 \\
78.95 & 286.05 & 79.04 & 0.10 & 3.95 \\
100.00 & 355.75 & 98.86 & -1.14 & 5.92 \\
\hline Average & - & - & 0.54 & 2.42 \\
\hline
\end{tabular}

Remark: All results were measured by the same laser pulse (300000 shot) regardless of the hydrogen gas concentration.

T a b l e 8. Summary of the hydrogen gas concentration measuring results according to the distance.

\begin{tabular}{llll}
\hline & $10 \mathrm{~m}$ & $20 \mathrm{~m}$ & $30 \mathrm{~m}$ \\
\hline Coefficient of determination $\left(R^{2}\right)$ & 0.9998 & 0.9998 & 0.9995 \\
Average measuring error & 0.40 & 0.43 & 0.54 \\
Standard deviation [\%] & 0.94 & 1.38 & 2.42 \\
\hline
\end{tabular}

rors are increased from 0.40 to 0.54 . In addition, standard deviations are increased from 0.94 to 2.42 and the coefficient of the determination of the linear trend line is decreased from 0.9998 to 0.9995 . The reason for these results is a laser pulse energy reduction according to the increasing laser emitting distance. 


\section{Conclusion}

A PC Raman lidar system for hydrogen gas detection was developed. A diode pumped laser and photon counter were used for an instrumentation of the Raman lidar system. To verify the performance of the developed PC Raman lidar system, experiments were carried out. The following conclusions were derived.

Typical Raman lidar systems used the high power laser source and large size telescope because the strength of Raman signal was affected by pulse laser power and telescope size. Comparing the previously developed Raman lidar system with the developed PC Raman lidar system, the latter uses very low power laser and small telescope. Therefore, the developed PC Raman lidar system can be miniaturized, which is not possible with the typical Raman lidar system for measuring the hydrogen gas concentration.

A developed PC Raman lidar system was able to measure the quantitative hydrogen gas concentration of 10 to $30 \mathrm{~m}$ by using the diode pumped laser which is $3 \mu \mathrm{J}$ pulse energy. Also, it was able to measure the 0.66 to $100 \mathrm{vol} \%$ hydrogen gas concentration at a distance of $30 \mathrm{~m}$. Comparing the $10 \mathrm{~m}$ with the $30 \mathrm{~m}$ experiments, the mean of the measurement error is slightly increased from 0.4 to 0.54 according to the increased measurement distance. In addition, the mean of the standard deviation is increased from 0.94 to 2.42 according to the increased measurement distance of 10 to $30 \mathrm{~m}$ but it is on a par with the performance of the typical Raman lidar system.

The hydrogen gas is a very important energy resource and will be commonly used in near future. However, the hydrogen gas is very dangerous because it is flammable and explosive even at a very low concentration. Therefore, a hydrogen gas leakage detection technique is essentially needed for its safe usage. The PC Raman lidar system will be one of the solutions.

Acknowledgment - This paper was supported by the Ministry of Science, ICT \& Future Planning.

\section{References}

[1] Shinn T., Hydrogen gas detection by mini-Raman lidar, [In] Ionizing Radiation Effects and Applications, [Ed.] B. Djezzar, InTech, 2018, pp. 41-60, DOI: 10.5772/intechopen.74630.

[2] Rosemont I.L., Barilo N., Wide Area Sensor Needs, DOE Hydrogen Sensor Workshop, Rosemont, IL, June 8, 2011.

[3] Wu S.H., Zhou H., Hao M.M., Wei X.B., Li S.B., Yu H., Wang X.R., Chen Z., Fast response hydrogen sensors based on anodic aluminum oxide with pore-widening treatment, Applied Surface Science 380, 2016, pp. 47-51, DOI: 10.1016/j.apsusc.2016.02.087.

[4] Yamazoe N., Toward innovations of gas sensor technology, Sensors and Actuators B: Chemical 108(1-2), 2005, pp. 2-14, DOI: 10.1016/j.snb.2004.12.075.

[5] Shen Y.B., Cao X.M., Zhang B.Q., Wei D.Z., Ma J.W., Liu W.G., Han C., Shen Y.T., Synthesis of $\mathrm{SnO}_{2}$ nanorods and application to $\mathrm{H}_{2}$ sensor, Journal of Alloys and Compounds 593, 2014, pp. 271 -274, DOI: $10.1016 /$ j.jallcom.2014.01.038.

[6] Korotcenkov G., Chо B.K., Engineering approaches to improvement of conductometric gas senor parameters. Part 2: decrease of dissipated (consumable) power and improment stability and reliability, Sensors and Actuators B: Chemical 198, 2014, pp. 316-341, DOI: 10.1016/j.snb.2014.03.069. 
[7] Comini E., Baratto C., Concina I., Faglia G., Falasconi M., Ferroni M., Galstyan V., Gobbi E., Ponzoni A., Vomiero A., Zappa D., Sberveglieri V., Sberveglieri G., Metal oxide nanoscience and nanotechnology for chemical sensors, Sensors and Actuators B: Chemical 179, 2013, pp. 3-20, DOI: 10.1016/j.snb.2012.10.027.

[8] Verem'ev R.N., Privalov V.E., Shemanin V.G., Optimization of a semiconductor lidar for detecting atmospheric molecular iodine and hydrogen, Technical Physics 45(5), 2000, pp. 636-640, DOI: $10.1134 / 1.1259691$.

[9] BaLl A.J., Investigation of Gaseous Hydrogen Leak Detection Using Raman Scattering and Laser -Induced Breakdown Spectroscopy, M.S. Thess, University of Florida, 2005.

[10] Asahi I., Sugimoto S., Ninomiya H., Fukuchi T., Shina T., Remote sensing of hydrogen gas concentration distribution by Raman lidar, Proceedings of SPIE 8526, 2012, article 85260X, DOI: $10.1117 / 12.977348$.

[11] Ninomiya H., Yaeshima S., Ichikawa K., Fukuchi T., Raman lidar system for hydrogen gas detection, Optical Engineering 46(9), 2007, article 094301, DOI: 10.1117/1.2784757.

[12] Choi I.Y., Baik S.H., Park N.G., Kang H.Y., Kim J.H., Improvement of the measuring accuracy of the raman lidar for remote detection of the hydrogen gas, International Journal of Precision Engineering and Manufacturing 19(7), 2018, pp. 967-973, DOI: 10.1007/s12541-018-0114-z.

[13] Limery A., Cezard N., Fleury D., Goular D., Planchat C., Bertrand J., Hauchecorne A., Raman lidar for hydrogen gas concentration monitoring and future radioactive waste management, Optics Express 25(24), 2017, pp. 30636-30641, DOI: 10.1364/OE.25.030636.

Received December 16, 2019 in revised form March 12, 2020 